\title{
Endocrine pancreas development is altered in foetuses from rats previously showing intra-uterine growth retardation in response to malnutrition
}

\author{
B. Blondeau, I. Avril, B. Duchene, B. Bréant \\ INSERM U 457, Hospital Robert Debré, Paris, France
}

\begin{abstract}
Aims/hypothesis. We have shown that perinatal malnutrition decreases beta-cell mass at birth and impairs the adaptation of the endocrine pancreas to a subsequent pregnancy. The aim of this study is to investigate the impact of this maternal inadaptation on the development of endocrine pancreas in foetuses. Methods. Female rats malnourished during their perinatal life and showing intra-uterine growth retardation at birth were mated at 8 months of age. The development of the endocrine pancreas was studied at embryonic days 14, 17 and 20 in their foetuses by immunohistochemistry and morphometrical measurements on pancreatic sections.

Results. At embryonic day 20, both alpha and betacell fractions were decreased in foetuses from IUGR dams. Beta-cell mass was reduced $(197 \pm 27 \mu \mathrm{g}$, vs $281 \pm 40 \mu \mathrm{g}$ in control, $p<0.01)$ and so were insulin content and islet number per $\mathrm{cm}^{2}$, as in the first generation foetuses. At embryonic day 14, the number of
\end{abstract}

cells expressing only insulin was decreased by half in foetuses from intra-uterine growth retardation dams. At embryonic day $17,50 \%$ of the homeodomain protein Pdx-1 cell population expressed insulin but all the insulin cells expressed Pdx-1 in both groups; in foetuses from intra-uterine growth retardation dams the number of epithelial cells expressing Pdx-1 was decreased $\left(415 \pm 40\right.$ cells $/ \mathrm{mm}^{2}$ vs $481 \pm 28$ cells $/ \mathrm{mm}^{2}$ in control foetuses, $p<0.05)$ and the mesenchymal fraction in the pancreas was increased by $36 \%$ $(p<0.05)$.

Conclusion/interpretation. Early malnutrition decreases beta-cell mass in the first generation of offspring and impairs the subsequent beta-cell adaptation to pregnancy. The beta-cell alteration is also present in the next generation and involves a decreased expansion of the epithelial population expressing Pdx-1. [Diabetologia (2002) 45: 394-401]

Keywords Endocrine pancreas, development, foetus, nutrition, rat, morphometry.
Proper foetal development requires an adequate maternal environment. It is now well known that maternal hyperglycaemia caused by gestational diabetes induces developmental disorders like macrosomia, hyperinsulinaemia and pancreatic islet hyperplasia in

Received: 16 July 2001 and in revised form: 17 October 2001

Corresponding author: Dr. B. Bréant, INSERM U 457, Hôpital Robert Debré, 48 boulevard Sérurier, 75019 Paris, France, e-mail: breant@idf.inserm.fr

Abbreviations: IUGR; Intra uterine growth retardation; F1IUGR dams, dams born with intra uterine growth retardation; $1 / 6$, ratio of fasting insulin values to blood glucose values the foetus [1]. These early alterations have been shown to be responsible for later disorders in adult life. In contrast, the concept of early programming of later chronic degenerative diseases like diabetes or glucose intolerance due to nutritional inadequacy in utero has developed during the last decade, prompted by epidemiological studies in humans $[2$, $3,4]$. In addition to the early settlement of insulin resistance as a plausible mechanism, the hypothesis of altered beta-cell development in utero has been proposed as a key factor for the later occurrence of dysregulations of glucose homeostasis during adulthood [5]. Experimental studies in animals sustain this notion of a causal link between malnutrition in utero 
and increased risk of glucose intolerance at adult age [6-8]. More specifically, pregnant rats fed a protein and calorie restricted or protein deficient diet only give birth to newborns with intra-uterine growth retardation (IUGR) and with fewer beta cells or with decreased islet volume $[9,10,11]$. We have designed a rat model of maternal general food restriction during the last third of pregnancy. The offspring were born with IUGR and a reduced beta-cell mass, a developmental alteration which could be ascribed to a defect in islet neogenesis [9]. When maternal food restriction is prolonged until weaning, the reduction of beta-cell mass is maximal and the defect cannot be compensated at adult age, despite ad libitum nutrition from weaning [12]. These early developmental beta-cell alterations, mainly acquired in utero, further generate inadequacies of the adult endocrine pancreas to adapt to situations of increased insulin demand. Hence, beta-cell growth is totally stunted during ageing in male rats and glucose intolerance develops due to a profound insulinopenia [8]. Female rats that have been malnourished during their foetal and early postnatal life also showed a reduced insulin response during an oral glucose challenge. Furthermore, they are not able to adapt their endocrine pancreas to a subsequent pregnancy at the age of 8 months, although they do not develop gestational diabetes [13]. This lack of maternal pancreatic adaptation to pregnancy is likely to have consequences on foetal development. The aim of this study is to observe the outcome of the foetuses issued from female rats at three stages of development, at embryonic days (E) 14, 17 and 20. Particular attention was given to the development of the endocrine pancreas in these foetuses.

\section{Materials and methods}

Animals and experimental design. Female Wistar rats on day 5 of pregnancy (Janvier breeding centre, Le Genêt-St-Isle, France) were housed individually and maintained under a 12h (0700-1900) light-dark cycle and at a constant temperature $\left(22^{\circ} \mathrm{C}\right)$. All animals were fed a standard laboratory rat chow (No. ${ }^{\circ} 113,22 \%$ protein, $5 \%$ fat, $53 \%$ carbohydrates; UAR, Villemoisson sur Orge, France), had free access to tap water and were randomly divided into two groups. Control pregnant dams were fed ad libitum whereas pregnant dams from the food restricted group were fed $50 \%$ the daily intake of the pregnant control dams from day 15 of pregnancy [9]. At parturition, pups born from food-restricted mothers and showing a severe intra-uterine growth retardation (IUGR) were selected [13] and maternal food restriction was continued until weaning in this group. After weaning, females from both groups were selected and fed ad libitum until adulthood. Adult females born with IUGR from mothers submitted to general food restriction will be referred to as F1-IUGR dams, whereas those born from normally fed mothers will be referred to as F1-control dams. At 8 months of age, F1-control and F1-IUGR dams were mated overnight with male control Wistar rats. The study has been carried out on the second generation foetuses from
F1-IUGR and F1-control dams. The experiments were carried out according to the "Principles of laboratory animal care", National Institutes of Health (NIH) and the French laws, authorisation No. 7612 delivered to B. Bréant by the French Agricultural Ministry.

Tissue processing. Pregnant F1 female rats from both groups were killed by cervical dislocation at days 14,17 and 20 of pregnancy. Fetal pancreatic buds were dissected at embryonic day (E) 14 and E17 and foetal pancreases at E20 were removed. For immunohistochemical analyses the tissues were fixed in a $3.7 \%$ formalin solution, processed using an automatic tissue processor (TP1020, Leica, Rueil Malmaison, France), and embedded in paraffin. Each pancreatic bud or pancreas was sectioned ( $6 \mu \mathrm{m}$ thick) throughout its length.

For measurements of pancreatic insulin content in each group at E20, seven pancreases of foetuses from five different mothers were sonicated in $3 \mathrm{ml}$ of cold acidified ethyl alcohol $(1.5 \% \mathrm{HCl}, 75 \% \mathrm{EtOH})$, insulin was extracted overnight at $-20^{\circ} \mathrm{C}$ and pancreatic remnants were subsequently centrifuged. The supernatant was kept at $-20^{\circ}$ until assayed.

Immunohistology and quantitative analysis. At E14, insulin and glucagon were simultaneously detected with antibodies raised in different species, a polyclonal guinea-pig anti-insulin antibody revealed with a FITC-conjugated anti-guinea pig antibody (Dako, Trappes, France) and a monoclonal mouse anti-glucagon antibody (Sigma, La Verpillière, France) revealed with a Texas red dye-conjugated anti-mouse antibody (Jackson Immunoresearch, Le Pont de Claix, France). At E14, total numbers of insulin, glucagon, or insulin and glucagon (double labelled cells) expressing cells were scored on every other section (i.e. every $12^{\text {th }} \mu \mathrm{m}$ ) to avoid counting the same cell twice. The results from six pancreatic buds of foetuses from three F1- IUGR-born or F1-control dams were averaged for each group.

At E17, total numbers of Pdx-1, insulin, or Pdx-1-insulin double expressing cells were counted on seven sections (every $72 \mu \mathrm{m}$ ) using a monoclonal mouse anti-insulin antibody (Sigma, La Verpillière, France) revealed with a Texas red dye-conjugated anti-mouse antibody (Jackson Immunoresearch) and a polyclonal anti-Pdx-1 antibody (kindly provided by Dr O.D. Madsen, Copenhagen, Denmark) revealed with a FITC-conjugated anti-rabbit antibody (Immunotech, Le Pont de Claix, France). After counting the number of fluorescent cells, the sections were slightly counterstained and the epithelial tissue area (excluding mesenchyme) or total tissue area (including mesenchyme) on the section were measured by morphometry using the Leica Q500MC system. The numbers of Pdx-1 or insulin cells per $\mathrm{mm}^{2}$ of epithelial tissue (excluding mesenchyme) were deduced from these measurements. To estimate the mesenchymal proportion in the pancreas, the ratio of the area occupied by the mesenchyme tissue to the area of the whole pancreas was calculated. The results from four to five pancreatic buds of foetuses from three F1- IUGR-born or F1control dams were averaged for each group.

Fluorescence was detected using a Leica DMRB microscope. Colocalization was determined by double immunofluorescence using a double-band filter (520-620 nm). Single labelled sections incubated with mismatched secondary antibodies showed no immunostaining, confirming the specificity of the secondary antibodies.

At E20, beta cells were detected with a polyclonal guinea pig anti-insulin antibody (Dako, Trappes, France) revealed after incubation with an alkaline phosphatase anti-rabbit antibody and visualised in blue with Nitroblue tetrazolium (Vector, AbCys, Paris, France). Alpha cells were detected with a 
Table 1. Insulinaemia and blood glucose concentrations in F1control and F1-IUGR dams before and during pregnancy

\begin{tabular}{lcc}
\hline & F1-control & F1-IUGR \\
\hline Non-pregnant & & \\
Glycaemia $(\mathrm{mmol} / \mathrm{l})$ & $7.0 \pm 1.2$ & $6.0 \pm 1.7$ \\
Insulinaemia $(\mathrm{nmol} / \mathrm{l})$ & $0.85 \pm 0.29$ & $0.56 \pm 0.28$ \\
$\mathrm{I} / \mathrm{G}\left(\times 10^{-9}\right)$ & $125 \pm 48$ & $102 \pm 57$ \\
Pregnant day 14 & & \\
Glycaemia $(\mathrm{mmol} / \mathrm{l})$ & $6.1 \pm 1.6$ & $5.5 \pm 1.1$ \\
Insulinaemia $(\mathrm{nmol} / \mathrm{l})$ & $1.59 \pm 0.19^{* *}$ & $0.79 \pm 0.31^{*}$ \\
$\mathrm{I} / \mathrm{G}\left(\times 10^{-9}\right)$ & $269 \pm 36^{* *}$ & $149 \pm 57^{*}$ \\
Pregnant day 20 & & \\
Glycaemia $(\mathrm{mmol} / \mathrm{l})$ & $4.1 \pm 0.3^{* *}$ & $3.9 \pm 0.5^{* *}$ \\
Insulinaemia $(\mathrm{nmol} / \mathrm{l})$ & $1.29 \pm 0.64^{* *}$ & $1.39 \pm 0.66^{* *}$ \\
I/G $\left(\times 10^{-9}\right)$ & $308 \pm 131^{* *}$ & $349 \pm 140^{* *}$ \\
\hline Plasma &
\end{tabular}

Plasma insulin concentrations were measured by radioimmunoassay on female rats from both groups, before pregnancy $(n=5)$ and at $14(n=3)$ and $20(n=5)$ days of pregnancy. Blood glucose concentrations were measured with Euroflash on the same animals. Results are expressed as means \pm SD $* p<0.05$ compared with controls

$* * p<0.05$ compared with the respective non-pregnant group, after an overall analysis using Kruskal Wallis followed by Mann-Whitney tests

Table 2. Weight and endocrine pancreas data from second generation foetuses at E20

\begin{tabular}{lcc}
\hline & $\begin{array}{l}\text { Foetuses from } \\
\text { F1-control } \\
\text { female rats }\end{array}$ & $\begin{array}{l}\text { Foetuses from } \\
\text { F1-IUGR } \\
\text { female rats }\end{array}$ \\
\hline Body weight $(\mathrm{g})$ & $3.4 \pm 0.4$ & $3.3 \pm 0.6$ \\
Pancreatic weight $(\mathrm{mg})$ & $13.7 \pm 3.6$ & $13.2 \pm 3.9$ \\
Alpha-cell fraction $(\%)$ & $0.53 \pm 0.06$ & $0.35 \pm 0.12^{*}$ \\
Alpha-cell mass $(\mu \mathrm{g})$ & $85.4 \pm 5.9$ & $56.5 \pm 27.9$ \\
$\begin{array}{l}\text { Average area of one islet }\left(\mu \mathrm{m}^{2}\right) \\
\text { Relative insulin content }\end{array}$ & $3046 \pm 256$ & $2725 \pm 195$ \\
(ng/mg pancreatic weight) & $204.5 \pm 92.2$ & $110.8 \pm 37.5^{*}$ \\
\hline Alpha
\end{tabular}

Alpha-cell fraction and mass and the average area of one islet were measured on five pancreas. Insulin contents were measured on seven pancreas by radioimmunoassay. Results are expressed as means $\pm \mathrm{SD}$

$* p<0.05$, compared with controls, analysed by Mann-Whitney test

monoclonal mouse anti-glucagon antibody (Sigma, La Verpillière, France) revealed after incubation with a peroxidase anti-mouse antibody and visualised in brown with 3, 3'-diaminobenzidine (Vector, AbCys). Beta-cell and alpha-cell fractions were measured by computer assisted measurements using a Leica DMRB microscope equipped with a colour video camera coupled to a Leica Quantimet 500MC computer (screen magnification $\times 24$ ) [12]. Briefly, beta-cell and alphacell fraction were measured as the ratio of insulin-positive or glucagon-positive cell area to the total tissue area on the entire section. In each group, five sections taken at $150 \mu \mathrm{m}$ intervals throughout the pancreas were analysed in five foetuses issued from 5 different mothers. Beta-cell or alpha-cell mass were obtained by multiplying beta-cell or alpha-cell fraction by the corresponding pancreatic weight. The number of islets (diameters within 25 to $600 \mu \mathrm{m}$ ) was also scored and expressed per $\mathrm{cm}^{2}$ of tissue. The average area of one islet was obtained by dividing the sum of insulin-positive and glucagon-positive area by the number of islets on the five sections analysed.

Insulin measurement. Immunoreactive insulin was measured with a radioimmunoassay (RIA), using monoiodated 125I-labelled porcine insulin (Sorin Biomedica, Salligia, Italy) as a tracer, guinea pig anti-insulin antibody (kindly provided by Dr. Van Schravendijk, Brussels, Belgium) and purified rat insulin (Novo, Boulogne, France) as standard. Charcoal was used to separate free from bound hormone. The sensitivity of the assay was $0.25 \mathrm{ng} / \mathrm{ml}(6 \mu \mathrm{U} / \mathrm{ml})$.

Blood glucose measurement. Blood glucose was measured on whole blood on F1 female rats with the glucometer Euroflash (Lifescan, Issy-Les-Moulineaux, France). It allows quick glucose assay using the glucose oxidase method.

Statistical analysis. Values are given as means \pm SD. Differences between groups were analysed using non-parametric tests, Mann-Whitney and Kruskal Wallis when there was more than two groups and considered significant at a $p$ value of less than 0.05 .

\section{Results}

Maternal glucose homeostasis in IUGR-born female rats. Maternal fasting glycaemia decreased whereas insulin values increased as pregnancy progressed in both groups of female rats (Table 1). Fasting blood glucose concentrations from F1-IUGR dams were not different from those of F1-control dams either before or at any time during pregnancy. However, fasting insulin values were decreased by half at day 14 of pregnancy in F1-IUGR dams $(p=0.03)$ compared to those of F1-control dams. Non-pregnant and pregnant day 20 insulin values were not different between both groups. The ratio of the insulin values to the blood glucose values (I/G) increased in the F1-control dams during pregnancy (day 14 and day 20 of pregnancy compared to the non-pregnant stage). This suggests that the insulin action decreases which could reflect insulin resistance, a well-known adaptation of pregnancy. At day 14 of pregnancy, the I/G ratio of F1-IUGR dams did not increase compared to the non-pregnant value and was decreased by half compared to the F1-control dams. But at day 20, the $\mathrm{I} / \mathrm{G}$ ratio of these dams increased and was not different to the ratio of F1-control dams (Table 1).

Foetal weight outcome. At E14, foetuses issued from F1-IUGR dams showed a slightly higher body weight $(0.16 \pm 0.02 \mathrm{~g})$ than foetuses from control females $(0.14 \pm 0.02 \mathrm{~g}, p<0.01)$. At E17 body weight did not differ between the two groups of foetuses, $788 \pm 21 \mathrm{mg}$ in foetuses from F1-IUGR females vs $767.4 \pm 45 \mathrm{mg}$ in foetuses from F1-control female rats. Neither body nor pancreatic weight differed between the two groups of foetuses at age E20 (Table 2). 
A

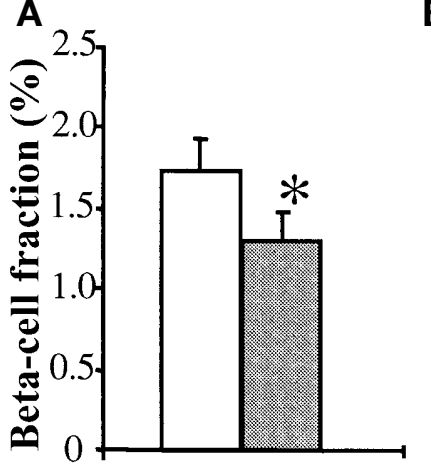

B

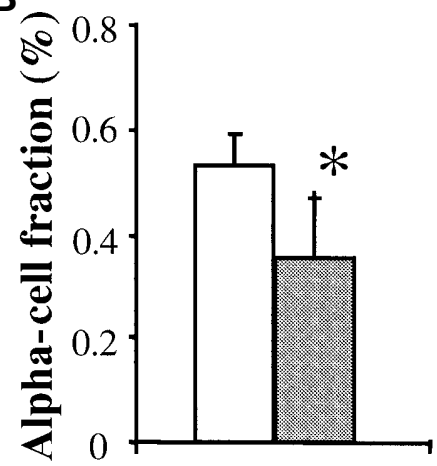

Fig. 1. Beta and alpha-cell fractions are decreased in E20 foetuses from F1-IUGR dams. Beta-cell (A) and alpha-cell (B) fractions were morphometrically measured after immunohistochemistry on pancreatic sections, as described in Materials and Methods, on foetuses ( $n=5)$ from control (open bars) or F1-IUGR (grey bars) females. Results are expressed as means \pm SD. ${ }^{*} p<0.05$ compared with controls
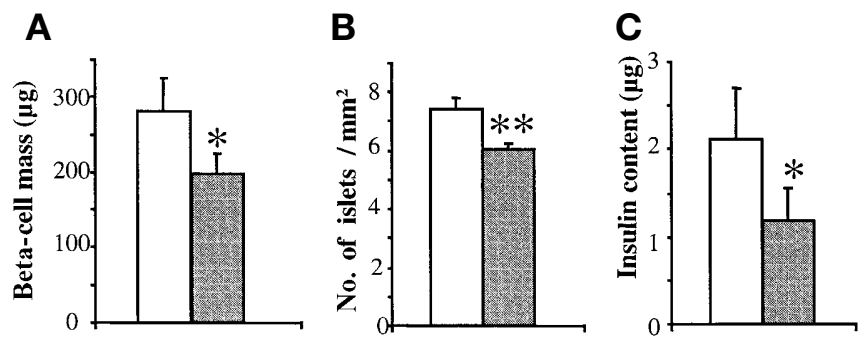

Fig. 2. Beta-cell mass, islet number and pancreatic insulin content are decreased in foetuses from F1-IUGR dams. Beta-cell mass at E20 (A) was calculated from the values of beta-cell fraction and pancreatic weight and the number of islets per $\mathrm{mm}^{2}$ (B) was morphometrically quantified on the same sections ( $n=5$ pancreases). Pancreatic insulin content per gland (C) was assessed by RIA in another set of pancreases $(n=7)$. Foetuses from control (open bars) and F1-IUGR (grey bars) females. Results are expressed as means $\pm \mathrm{SD}$. ${ }^{*} p<0.05$, $* * p \leq 0.01$ compared with controls

Alpha- and beta-cell fraction in E20 foetuses from F1IUGR dams. The morphometric analysis of the pancreas at E20 showed a decreased alpha-cell fraction in foetuses from F1-IUGR dams ( $p=0.03$, Fig. 1B), leading to a tendency to a decreased alpha-cell mass $(p=0.10$, Table 1$)$ compared to foetuses from F1control female rats. In a similar way, beta-cell fraction was also decreased in the foetuses from F1-IUGR females compared to the control rats (Fig.1A). The beta-to-alpha cell ratio (approximately three times more beta than alpha cells) was not different between the two animal groups. Beta-cell mass was decreased $(p=0.02$, Fig $2 \mathrm{~A})$ and this reduction was associated to a lower numerical density of islets (number of islets $/ \mathrm{cm}^{2}, p=0.01$, Fig. 2B) of similar size (Table 2) in foetuses from F1-IUGR dams in comparison with those of foetuses from the control female rats. Additionally, there was a $50 \%$ decrease in the absolute
Table 3. Morphometric parameters from second generation foetuses at E17

\begin{tabular}{lcc}
\hline & $\begin{array}{l}\text { Foetuses from } \\
\text { F1-control } \\
\text { female rats }\end{array}$ & $\begin{array}{l}\text { Foetuses from } \\
\text { F1-IUGR } \\
\text { female rats }\end{array}$ \\
\hline $\begin{array}{l}\text { \% of Pdx-1 cells expressing } \\
\text { insulin } \\
\text { \% of insulin cells expressing }\end{array}$ & $50 \pm 10$ & $46 \pm 7$ \\
$\begin{array}{l}\text { Pdx-1 } \\
\text { Mesenchymal fraction } \\
\text { (\% of the pancreas) }\end{array}$ & $93 \pm 0.5$ & $92 \pm 0.5$ \\
$\begin{array}{l}\text { Number of Pdx-1 cells } / \mathrm{mm}^{2} \\
\text { Number of insulin cells } / \mathrm{mm}^{2}\end{array}$ & $481 \pm 28$ & $56.1 \pm 7.7^{*}$ \\
\hline
\end{tabular}

The morphometric parameters were analysed on four to five pancreas after double immunohistochemistry. Results are expressed as means $\pm \mathrm{SD}$

${ }^{*} p<0.05$, compared with controls, using Mann-Whitney test

(Fig. 2C) and relative (Table 2) pancreatic insulin content.

Precursor cells in foetuses from F1-IUGR dams. To find a mechanistic explanation for the decreased beta-cell mass at E20, earlier foetal stages were investigated. Total numbers of cells immunoreactive for insulin or glucagon were similar in pancreatic buds of E14 foetuses from F1-IUGR and F1-control females and showed three times more glucagon than insulin cells (Fig. 3), a normal alpha-to-beta cell ratio at that foetal stage. Double immunofluorescence showed numbers of cells coexpressing both hormones in both animal groups (Fig. $3 \mathrm{~A}-\mathrm{C}$ ), which did not express the transcription factor Pdx-1 (Fig.3 E-G). However, the number of cells expressing only insulin was decreased by half in second-generation foetuses from F1-IUGR females ( $p=0.02$, Fig. 3D). In both groups, the majority of the epithelial cells from the pancreatic bud expressed Pdx-1 (Fig. 3 E, G) but none of the Pdx-1 positive cells expressed glucagon (Fig 3. E, F). Pdx-1-positive cells rarely expressed insulin (less than $1 \%$ of the cells, i. e. five per pancreatic bud, Fig 3. H, I). Given the small number of the double positive Pdx-1 and insulin cells) at this early stage, this observation could not be reliably quantified and compared between the two animal groups.

However, as differentiation proceeded, the number of insulin-positive cells had increased at E17. At that stage, nearly all insulin cells expressed Pdx-1 but only half of the Pdx-1-positive cells expressed insulin (Fig. 4A-C); these ratios were similar in both animal groups (Table 3 ). The number of Pdx-1 positive cells per $\mathrm{mm}^{2}$ of epithelial tissue was decreased in foetuses from F1-IUGR females compared to that of foetuses from F1-control females $(p=0.05$, Table 3, Fig. 4B-C), and so was the number of insulin positive cells per $\mathrm{mm}^{2}$ of tissue $(p=0.05$, Table 3$)$. Of interest, in foetuses from F1-IUGR females the 

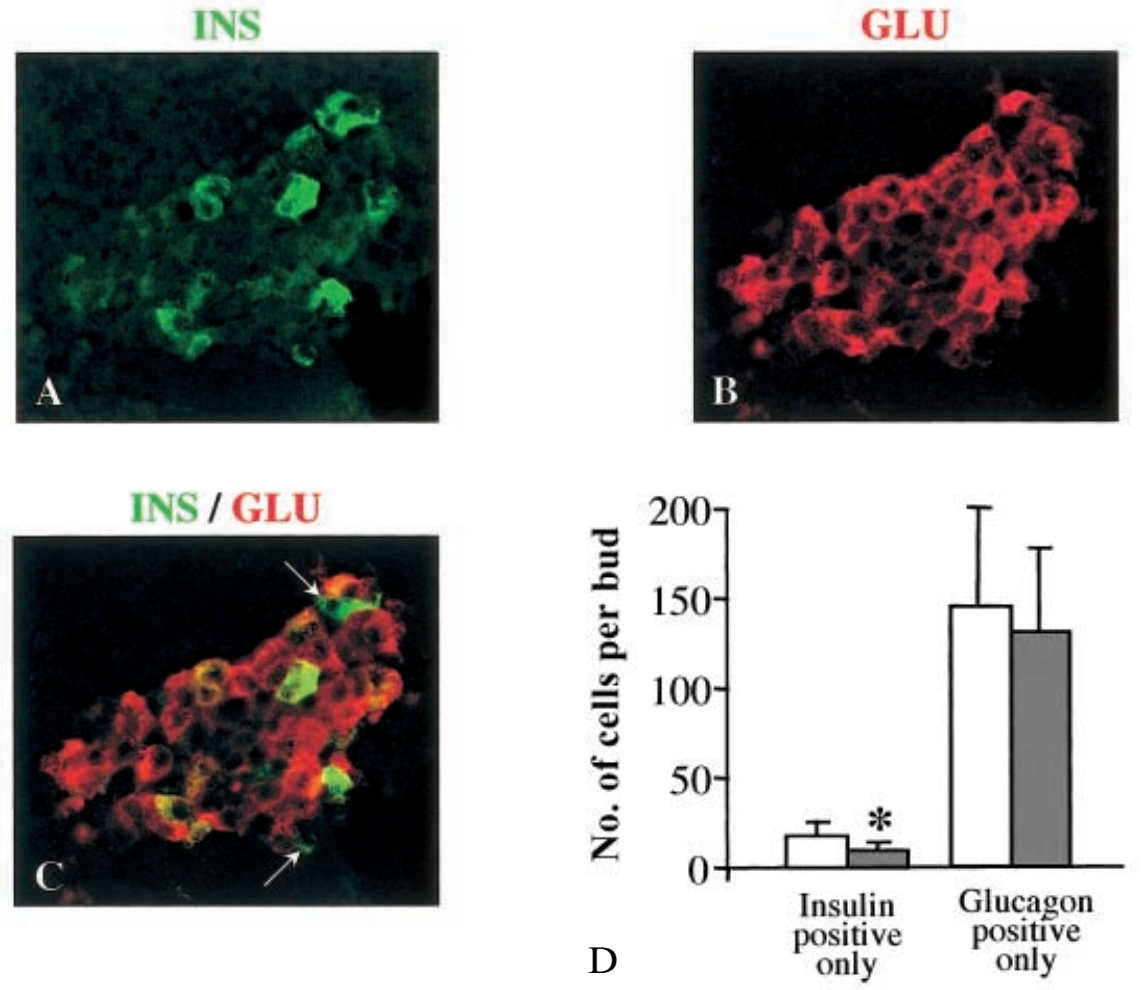

\section{GLU / PDX-1}

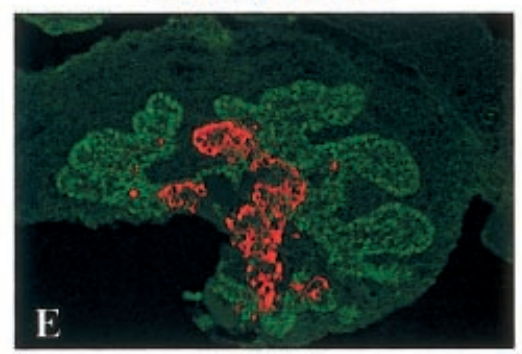

PDX-1

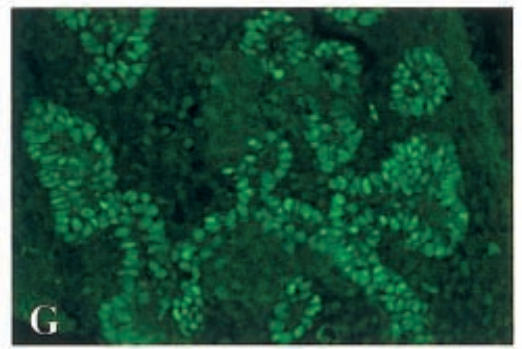

Fig. 3 (A-I). Foetuses from F1-IUGR dams show fewer insulin-positive cells at E14. Detection of insulin-expressing cells (A, green), glucagon-expressing cells $(\mathbf{B}$, red) and cells coexpressing both hormones ( $\mathbf{C}$, yellow) in a pancreatic bud of a foetus from F1-IUGR dam at E14; original magnification $\times 1042$. At this stage glucagon cells are the most abundant and many insulin-expressing cells also express glucagon; D quantification of cells expressing only insulin or glucagon in E14 pancreatic buds of foetuses from control (open bars) and F1-IUGR (grey bars) dams. Results are expressed as mean

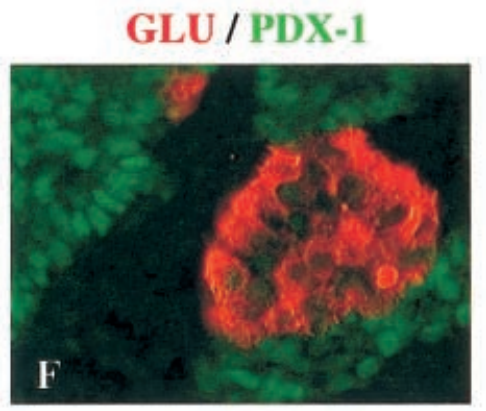

INS / PDX-1

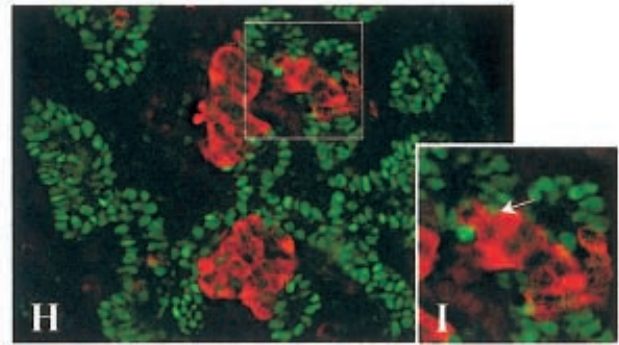

cell numbers \pm SD per bud $(n=6)$. Foetuses from F1-IUGR females show fewer cells immunopositive for insulin only (indicated by arrows in $\mathbf{C}$ ), $* p<0.05$ compared with controls. $\mathbf{E}$ and $\mathbf{F}$, detection of Pdx-1-positive cells (green) and glucagonpositive cells (red) in a pancreatic bud at E14, original magnification $\times 260(\mathbf{E})$ and $\times 1042(\mathbf{F})$; G-I, detection of Pdx-1-positive cells (green) and insulin cells (red), original magnification $\times 521(\mathbf{G}, \mathbf{H})$ and $\times 1042(\mathbf{I})$. Insulin expression in Pdx-1 positive cells is a rare event (arrow in $\mathbf{I}$ ) 

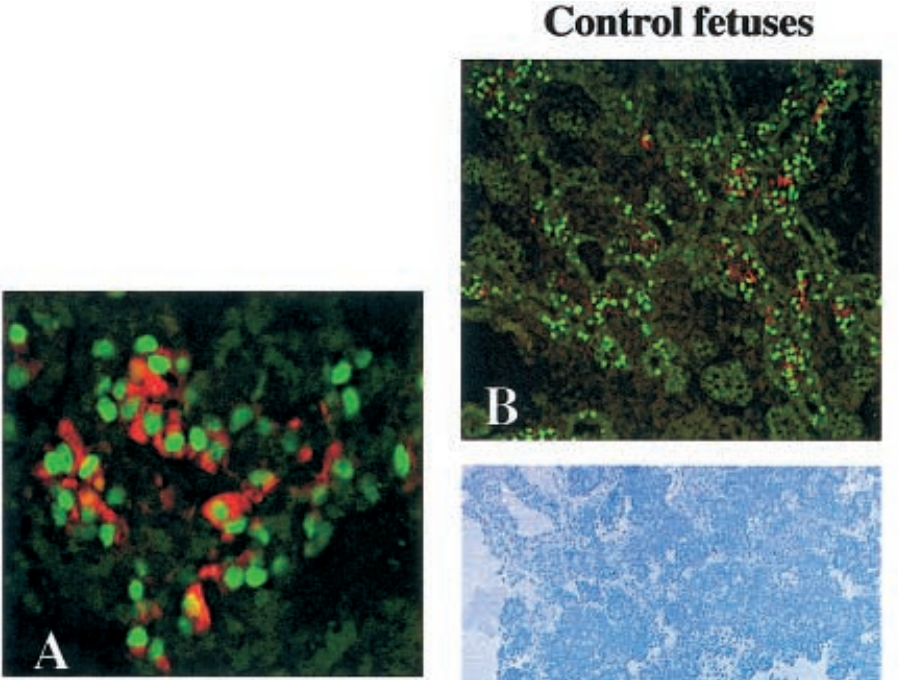

\section{Fetuses from IUGR dams}
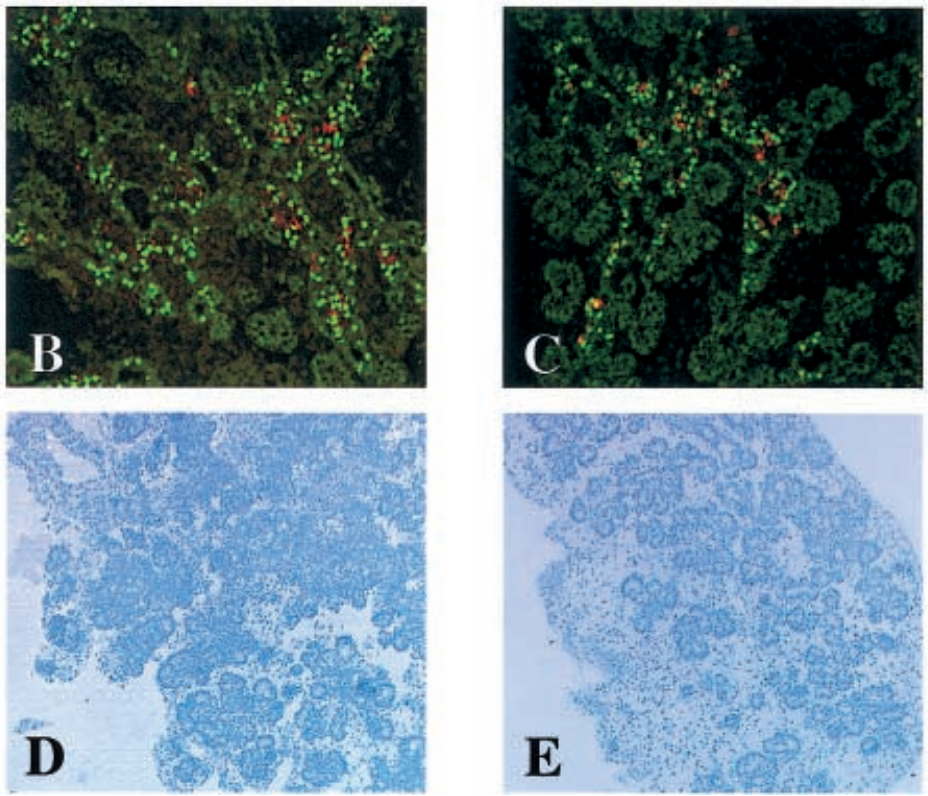

Fig. 4 (A-E). Decreased numbers of Pdx-1-positive cells in foetuses from F1-IUGR dams at E17. Detection of Pdx-1-positive cells (green) and insulin cells (red) in foetuses from control dams (B) and F1-IUGR $(\mathbf{A}, \mathbf{C})$ dams at E17, original magnification $\times 1042(\mathbf{A})$ and $\times 521(\mathbf{B}, \mathbf{C})$. Counterstaining on E17 pancreatic sections showing increased proportion of mesenchyme compared to epithelium in foetuses from F1-IUGR dams (E) compared to foetuses from control dams (D), original magnification $\times 260$

mesenchymal fraction in the pancreas was increased by $36 \%$ ( $p=0.02$, Table 3 , Fig. 4D-E).

\section{Discussion}

We have previously shown that female rats malnourished during their perinatal life have decreased betacell mass at birth and are not able to adapt their endocrine pancreatic mass to pregnancy at 8 months of age. In this study we show that this lack of adaptation is associated with abnormal alpha- and beta-cell development in their foetuses, probably due to impaired expansion of the precursor cell population. Perinatal malnutrition in the first generation therefore has consequences on second-generation foetal pancreatic development.

We show that foetuses from IUGR-born female rats present decreased alpha- and beta-cell fraction at E20. The decreased beta-cell mass was associated with a decreased islet numerical density, suggesting a decreased absolute number of islets per pancreas. This alteration, which is likely to reflect an impairment of islet neogenesis, was already observed in the first generation neonates [9].
To explain mechanistically the phenotype observed at E20, we investigated earlier stages of pancreatic development. At foetal stage E14, the number of cells expressing only insulin in the foetuses from IUGRborn female rats was half that of control foetuses and the proportion of cells co-expressing insulin and glucagon was higher than in the control foetuses. The significance of the double positive insulin and glucagon cells is still obscure and there is no direct evidence [14-17] to support the notion that they could be precursors [18]. Moreover, it has been shown that adult insulin producing and glucagon producing cells in mice differentiate from independent cell lineages and that beta cells never go through a phase of glucagon gene activity [17]. To better characterize endocrine cells at this stage, we studied their status of Pdx-1 expression. We have shown that in the normal E14 foetal rat pancreas, most of the insulin producing cells do not express Pdx1 (or express Pdx-1 below the limit of detection of the antibody used in this study). This result suggests that at this stage, two populations of insulin expressing cells exist, one with and one without the Pdx-1 expression. The meaning of this observation has not been determined but could represent a marker of maturity. In mice with a global knockout for Pdx-1, some cells producing insulin or glucagon can be found at early stages (E11), despite the absence of a pancreas at birth. Moreover, in normal mouse foetuses, the majority of the insulin-positive cells at E11 were shown to be Pdx-1 negative or to express this protein at a low level [19]. Our study shows that this result is also found in the foetal rat pancreas. Because of the low number of cells expressing insulin and Pdx-1 at this stage, this observation is not reliable enough to be used as a quantitative parameter between foetuses from IUGR-born females and control foetuses. 
The observations at E17 were also informative. An increased mesenchyme to epithelium ratio was observed in foetuses from F1-IUGR female rats. The presence of mesenchyme has been shown to inhibit the differentiation of pancreatic epithelial cells into endocrine cells in a model of cultured pancreatic bud [20]. In our model, increased inhibition of endocrine differentiation by the mesenchyme could contribute to the phenotype observed at E20. In addition, a decreased number of cells expressing Pdx-1, which are likely to be precursors for endocrine cells, were also noted at E17 in foetuses from F1-IUGR female rats. A decreased number of precursor cells could, at least in part, lead to decreased alpha and beta-cell fractions later at E20.

How the maternal lack of pancreatic adaptation can influence the foetal pancreatic development is not known. The foetal development requires a continuous and increased flux of glucose throughout the entire pregnancy. To achieve this, insulin resistance takes place in the mother, resulting in modifications of the maternal beta-cell function and plasticity [21]. If these modifications do not occur, the maternal metabolic status cannot adapt to pregnancy, resulting in maternal glucose homeostasis disorders that are known to have deleterious consequences on foetal development. Using the ratio of insulin to glucose blood concentrations ( $\mathrm{I} / \mathrm{G})$ as an index of insulin resistance, we observed that this ratio increased at day 14 of pregnancy in the control mothers, suggesting that insulin resistance took place normally; however, in the F1-IUGR dams, the $\mathrm{I} / \mathrm{G}$ ratio did not increase until 20 days of pregnancy, suggesting a delayed insulin resistance, likely to alter the maternal metabolism. We cannot exclude that this event could be responsible for the impaired foetal endocrine pancreas development observed.

It is interesting to compare our results to the GotoKakisaki (GK) rat model of non-insulin-dependent diabetes. The selective breeding of animals showing glucose intolerance in a normal Wistar rat colony over more than 30 generations resulted in the spontaneous appearance of Type II (non-insulin-dependent) diabetes mellitus in adult rats [22]. Furthermore the decreased beta-cell mass observed as early as at foetal stages in the GK rat persists throughout life [23], suggesting that pancreatic alterations and Type II diabetes can be transmitted through generations. We did not explore the outcome of the foetuses from F1-IUGR dams after birth or later in their life and further follow-up experiments would be required to study whether the transmission of the beta-cell abnormal development could also be associated with impaired glucose tolerance at adulthood.

In conclusion, the lack of maternal pancreatic adaptation to pregnancy due to early malnutrition has consequences on foetal endocrine pancreas development in the rat. Whether these transmittable, though not genetic, alterations arise from perturbations of the foetal metabolic environment or altered growth factor disposal remains to be clarified. It seems likely that in this animal model, the second-generation foetuses with a decreased beta-cell mass will not adapt properly to a subsequent pregnancy, thereby perpetuating the pancreatic alterations through generations. Transmission of impaired glucose homeostasis from one generation to another without any genetic environment, already shown during experimental diabetic pregnancies [24], is also suggested as a consequence of in utero malnutrition. Considering the results obtained on second generation foetuses from this animal model, great attention should be given to pregnant women born with IUGR, by means of both maternal and foetal follow-up investigations during pregnancy.

Acknowledgements. This work was funded by the Institut National de la Santé et de la Recherche Médicale (INSERM). B. Blondeau and I. Avril are doctoral recipients of Ministère de l'Education Nationale, de la Recherche et de la Technologie. The authors are grateful to Dr O.D. Madsen for providing us with the anti-Pdx-1 antibodies. We are indebted to Prof. P. Czernichow for his constant support and helpful discussions.

\section{References}

1. Van Assche FA, Holemans K, Aerts L (1998) Fetal growth and consequences for later life. J Perinat Med 26: 337-346

2. Hales CN, Barker DJ, Clark PM et al. (1991) Fetal and infant growth and impaired glucose tolerance at age 64 . BMJ 303: 1019-1022

3. Barker DJ, Hales CN, Fall CH, Osmond C, Phipps K, Clark PM (1993) Type II (non-insulin-dependent) diabetes mellitus, hypertension and hyperlipidaemia (syndrome $\mathrm{X})$ : relation to reduced foetal growth. Diabetologia 36 : 62-67

4. McCance DR, Pettit DJ, Hanson RL, Jacobsson LTH, Knowler WC, Benett PH (1994) Birth weight and non-insulin dependent diabetes : thrifty genotype, thrifty phenotype, or surviving small baby genotype ? BMJ 308: 942-945

5. Hales CN, Barker DJ (1992) Type II (non-insulin-dependent) diabetes mellitus: the thrifty phenotype hypothesis. Diabetologia 35: 595-601

6. Dahri S, Snoeck A, Reusens-Billen B, Remacle C, Hoet JJ (1991) Islet function in offspring of mothers on low-protein diet during gestation. Diabetes 40 [Suppl 2]: 115-120

7. Escriva F, Rodriguez C, Cacho J, Alvarez C, Portha B, Pascual-Leone AM (1992) Glucose utilization and insulin action in adult rats submitted to prolonged food restriction. Am J Physiol 263: E1-E7

8. Garofano A, Czernichow P, Bréant B (1999) Effect of ageing on beta-cell mass and function in rats malnourished during the perinatal period. Diabetologia 42: 711-718

9. Garofano A, Czernichow P, Breant B (1997) In utero undernutrition impairs rat beta-cell development. Diabetologia 40: 1231-1234

10. Martin MA, Alvarez C, Goya L, Portha B, Pascual-Leone AM (1997) Insulin secretion in adult rats that had experienced different underfeeding patterns during their development. Am J Physiol 272: E634-E640 
11. Snoeck A, Remacle C, Reusens B, Hoet JJ (1990) Effect of a low protein diet during pregnancy on the foetal rat endocrine pancreas. Biol Neonate 57: 107-118

12. Garofano A, Czernichow P, Breant B (1998) Beta-cell mass and proliferation following late foetal and early postnatal malnutrition in the rat. Diabetologia 41: 1114-1120

13. Blondeau B, Garofano A, Czernichow P, Breant B (1999) Age-dependent inability of the endocrine pancreas to adapt to pregnancy: a long-term consequence of perinatal malnutrition in the rat. Endocrinology 140: 4208-4213

14. Teitelman G, Alpert S, Polak JM, Martinez A, Hanahan D (1993) Precursor cells of mouse endocrine pancreas coexpress insulin, glucagon and the neuronal proteins tyrosine hydroxylase and neuropeptide $\mathrm{Y}$, but not pancreatic polypeptide. Development 118: 1031-1039

15. Ahlgren U, Pfaff SL, Jessell TM, Edlund T, Edlund H (1997) Independent requirement for ISL1 in formation of pancreatic mesenchyme and islet cells. Nature 385: 257-260

16. Jensen J, Heller RS, Funder-Nielsen T et al. (2000) Independent development of pancreatic alpha- and beta-cells from neurogenin3-expressing precursors: a role for the notch pathway in repression of premature differentiation. Diabetes 49: 163-176

17. Herrera PL (2000) Adult insulin- and glucagon-producing cells differentiate from two independent cell lineages. Development 127: 2317-2322

18. Alpert S, Hanahan D, Teitelman G (1988) Hybrid insulin genes reveal a developmental lineage for pancreatic endo- crine cells and imply a relationship with neurons. Cell 53: 295-308

19. Ahlgren U, Jonsson J, Edlund H (1996) The morphogenesis of the pancreatic mesenchyme is uncoupled from that of the pancreatic epithelium in IPF1/PDX1-deficient mice. Development 122: 1409-1416

20. Miralles F, Czernichow P, Scharfmann R (1998) Follistatin regulates the relative proportions of endocrine versus exocrine tissue during pancreatic development. Development 125: $1017-1024$

21. Sorenson RL, Brelje TC (1997) Adaptation of islets of Langerhans to pregnancy: beta-cell growth, enhanced insulin secretion and the role of lactogenic hormones. Horm Metab Res 29: 301-307

22. Goto Y, Kakisaki M, Masaki N (1975) Spontaneous diabetes produced by repeated selective breeding of normal Wistar rats. Proc Jpn Acad 51: 80-85

23. Movassat J, Saulnier C, Serradas P, Portha B (1997) Impaired development of pancreatic beta-cell mass is a primary event during the progression to diabetes in the GK rat. Diabetologia 40: 916-925

24. Aerts L, Sodoyez-Goffaux F, Sodoyez JC, Malaisse WJ, Van Assche FA (1988) The diabetic intrauterine milieu has a long-lasting effect on insulin secretion by B cells and on insulin uptake by target tissues. Am J Obstet Gynecol 159: $1287-1292$ 